\title{
Driver behavior analysis on a curve through immersive simulation and a segmented regression model
}

\section{Análise do comportamento do motorista em uma curva por meio de simulação imersiva e um modelo de regressão segmentado} \author{
Maurício Roberto Veronez ${ }^{8}$ \\ 1 Unisinos University, Rio Grande do Sul - Brazil, leonardoscalco@unisinos.br \\ 2Unisinos University, Rio Grande do Sul - Brazil, fabianebor@unisinos.br \\ ${ }^{3}$ State University of Maringá, Paraná - Brazil, eniucemenezes@gmail.com \\ ${ }^{4}$ Unisinos University, Rio Grande do Sul - Brazil, gracielarr@unisinos.br \\ 5Unisinos University, Rio Grande do Sul-Brazil, adejunior@edu.unisinos.br \\ 6University of Ceará, Ceará - Brazil, flaviocunto@det.ufc.br \\ 7Unisinos University, Rio Grande do Sul - Brazil, Igonzaga@unisinos.br \\ 8Unisinos University, Rio Grande do Sul-Brazil, veronez@unisinos.br
}

Leonardo Scalco ${ }^{1}$, Fabiane Bordin², Eniuce Menezes de Souza ${ }^{3}$, Graciela Racolte ${ }^{4}$, Ademir Marques Jr ${ }^{5}$, Flávio José Craveiro Cunto ${ }^{6}$, Luiz Gonzaga da Silveira Jr ${ }^{7}$,

\section{Recebido:}

26 de janeiro de 2021

Aceito para publicação:

17 de julho de 2021

Publicado:

11 de fevereiro de 2022

Editor de área:

Sara Ferreira

\section{Keywords:}

Traffic accidents.

Behavior evaluation.

Virtual Reality.

Palavras-chave:

Acidentes de trânsito.

Análise de comportamento.

Realidade Virtual.

DOI:10.14295/transportes.v30i1.2548

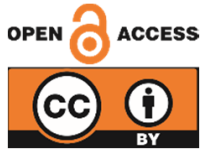

\begin{abstract}
Considering all the elements related to the occurrence of accidents, an important aspect is to identify the drivers most prone to accidents. This study aims to evaluate the behavior of drivers concerning gender and age. For this, a stretch of highway with a dangerous curve was modeled in a simulator using an immersive virtual environment and 59 people experienced the simulation. The car speed was registered along the route and from a segmented regression model, the behavior for both groups was evaluated regarding average speed. The results showed that older drivers (26 to 35 years old) of the female gender slowed the car before the other profile groups. Also, younger drivers (18 to 25 years old) took longer to slow down and had more accidents in the simulations. These results show that there are differences in driver's behavior concerning gender and age.
\end{abstract}

\section{RESUMO}

Considerando todos os elementos que podem estar relacionados à ocorrência de acidentes é importante identificar o perfil dos motoristas mais sujeitos a eles. Esta pesquisa teve como objetivo avaliar as diferenças no comportamento dos motoristas em relação ao gênero e à idade. Para isso, um trecho de rodovia com uma curva considerada perigosa foi modelado em um simulador usando ambiente virtual imersivo e 59 pessoas experimentaram a simulação. A velocidade do carro foi registrada ao longo do percurso e a partir de um modelo de regressão segmentado avaliou-se o comportamento dos grupos em relação à velocidade média. Foi possível verificar que mulheres mais velhas ( 26 a 35 anos) reduziram a velocidade antes em comparação aos demais motoristas. Além disso, homens mais jovens (18 a 25 anos) demoraram mais para frear e tiveram mais acidentes nas simulações. Os resultados mostram que existem diferenças de comportamento dos motoristas em relação ao seu perfil. 


\section{INTRODUCTION}

According to statistics from the World Health Organization - WHO (2018), traffic accidents are responsible for more than 1.35 million deaths every year. The causes of accidents are wide, so extensive research is needed to know and analyze all possible factors (Savolainen et al., 2011). In this context, broader research is needed to understand traffic safety, which is a result of an interaction between design factors, technology, the environment, and driver behavior (Perrels et al., 2015).

Some studies showed that age and gender have a major impact on how drivers behave under certain conditions (Clarke et al., 2006; Rhodes and Pivik, 2011; Dafrallah et al., 2020). According to the WHO (2018), most of the accident victims are less than 29 years old. A survey carried by Rhodes and Pivik (2011) found that young age people and male drivers appear to be more reckless when compared to older people and women drivers. In addition, the authors also found that men have a lower perception of danger in risk situations than women. In another work, Clarke et al. (2006) analyzed a database of over 3000 accidents assessing the influence of gender and lack of experience on driving behavior. The authors considered a group between 17 and 25 years old and found that men under 20, driving on dimly lit road curves, are more likely to be involved in accidents, with the main causes of accidents been speeding and recklessness. The works of Roman et al. (2015) and McCartt et al. (2009) also showed similar results to the works of Clarke et al. (2006) and Rhodes and Pivik (2011).

However, a research method that encompasses all variables of human behavior is difficult to achieve (Mannering, Shankar and Bhat, 2016). On the highways, the physical and mental abilities, the risk perception in certain situations, and reaction times vary greatly for each individual (Mannering, Shankar and Bhat, 2016). For that reason, it is important to understand the factors that can influence driving behavior. Several studies have shown correlations between accidents and characteristics of gender and age of drivers. These studies are mostly based on databases that store the history of traffic accidents, nevertheless, practical research related to driver's behaviors should be extended to precede accidents occurrence (Matar and Al-Mutairi, 2020). However, studies carried on existing highways are not safe for participants because is not possible to control all variables (environmental and behavioral). Therefore, this scenario increases the importance of driving simulators in this kind of study and the advantages of carrying experiments in a safe and controlled environment using virtual reality (VR) simulators (Taheri et al., 2017).

The VR simulators can be described as simulation environments that use realistic 3D scenarios where the user interacts through driving controls (steering wheels and pedals) and has immersive visual response using VR headsets that track the users head position (Dickey, 2005; Bella, 2008; Ihemedu-Steinke et al., 2017). This tool became important due to its ability to give prior handling experience and feeling of a real scenario to its users (Tori, Kirner and Siscoutto, 2006; Lee et al., 2007). In terms of complexity, the driving simulators can be divided into basic, intermediate, and high-fidelity levels, depending on the realism and the application of the simulation (Lucas et al., 2013). Over time, many studies have been conducted to validate virtual reality and driving simulators in the field of traffic, showing excellent results (Meuleners and Fraser, 2015; Taheri et al., 2017). Some of its application analyzes the distractions caused to drivers using cell phones while driving and evaluate the use of the tool with more than one driver, for example (Oeltze and Schießl, 2015; Farah et al., 2016; Morley, Lawrence and Smith, 2016; Vieira and Larocca, 2017). 
In recent studies, driving simulators have been used to compare driver behavior in accidents analysis. The comparison of age and gender in VR simulators has great advantages and shows that driving experience changes traffic speed (Branzi, Domenichini and La Torre, 2017). This study is similar to the work of Chaudry (2020) which aimed to evaluate human behavior but focused on driving the perception and experience of each of the only 15 participants. In the work of Goedicke et al. (2018), a virtual reality environment was created positioning the participants in a real car while the simulation was conducted, however, the overall study was limited both in its analysis and statistical power. Another related work of Peng et al. (2018) has the same statistical drawbacks. This research evaluated driving perception and driving experience but used small sample sizes and had very limited analyzes, lacking, consequently, statistical power (Goedicke et al., 2018; Peng et al., 2018; Chaudry, 2020).

Given this context, this paper is based on the supposition that the virtual environment can reproduce a risky road stretch to evaluate the behavior of drivers regarding speed changes considering their gender and age. To overcome the small sample sizes and limited analyses that have been performed in general in the literature, we computed the minimum sample size as well as carried out an analysis using a segmented regression model to detect changes in speed along a road stretch recreated in a VR simulation environment.

\section{MATERIAL AND METHODS}

In this study a curved road stretch located at kilometer 47 in the RS-122 road in the city of Farroupilha, in the state of Rio Grande do Sul, Brazil, was modeled in an immersive virtual environment (Figure 1). In Figure 1, the points A, B, C, D, E, and F correspond to traffic signs for the $50 \mathrm{~km} / \mathrm{h}$ speed limit and the sharp bend ahead. The stretch between the points $\mathrm{G}$ and $\mathrm{H}$ is where the sharp bend is. At the same point $G$, there is a radar speed trap of $50 \mathrm{~km} / \mathrm{h}$. This area was used due to the high occurrence of accidents, mostly because of the existence of the sharp curve with no visibility to the other side inflicting a high possibility of frontal crashes if the driver crosses the lane. According to the road authority databases, the ERS-122 road is one of the state's roads with the most accidents and casualties in the Rio Grande do Sul state (Comando Rodoviário da Brigada Militar - CRBM, 2021). For this area only, 246 fatal accidents have been registered in the last 11 years (2010 - 2020). The peak of accidents occurred between 2010 until 2015. In 2016, a radar speed trap was installed, reducing the occurrence of accidents, however, the number of accidents is still high.

This RS-122 stretch is known as the death's curve due to the high rates of accidents. This $180^{\circ}$ curve has a length of 203 meters, and a radius of 100 meters ( 0.06 miles), in 1225 meters ( 0.76 miles). This road stretch has three lanes, with two in one direction, and one in the other direction (lane used in the simulation). Each lane has 3.6 meters of width and a road shoulder in both directions of 1.5 meters.

The stretch was reconstructed on Bentley's OpenRoads ConceptStation ${ }^{\circledR}$ and OpenRoads Designer ${ }^{\circledR}$ platforms (Bentley / OpenRoads - Transportation, Civil Analiys, Design Software, 2021), which allow for detailed geometric reconstructions and integration of georeferenced satellite data. All vertical speed limit and sharp bend warning signs were identified and modeled in the Autodesk Maya ${ }^{\circledR}$ software (Autodesk / Education Community, 2021), widely used in the computational area for modeling, simulation, 3D rendering, and animation. The simulation environment was recreated on the Unity $3 \mathrm{D} \AA$ game engine 
(Unity Real-Time Development Platform / 3D, 2D VR \& AR Engine, 2021), importing the modeled 3D objects, physics, virtual cameras, and controls to create an immersive realistic environment.

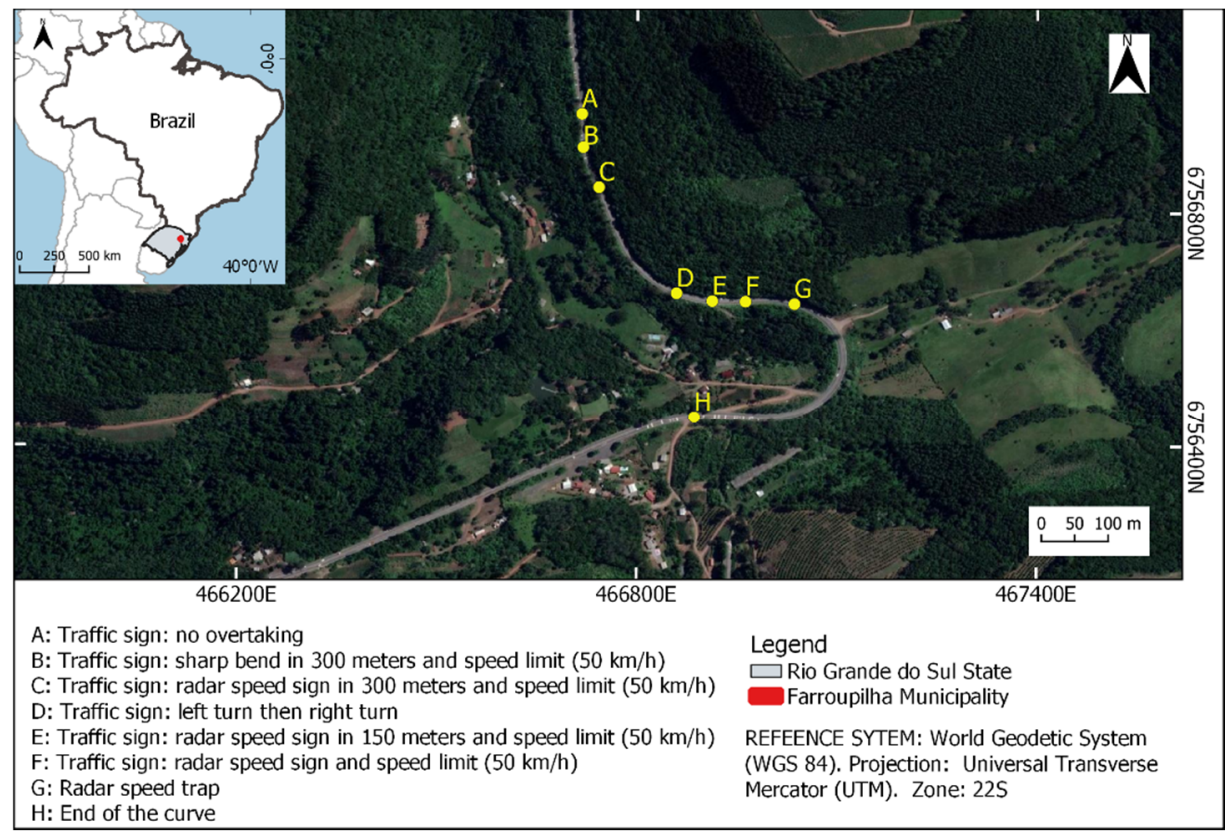

Figure 1. Study area localization in the city of Farroupilha/RS, Brazil. A, B, C, D, E, and F correspond to the traffic signs, $\mathrm{G}$ is the radar speed trap and $\mathrm{H}$ is the end of the curve

The vegetation, important for the perception of speed, was placed along the geometric tracing to follow the approximate densities found in the real environment, both in positioning and in shape. The final scenario with vegetation and traffic signs is shown in Figure 2B. Invisible markers (colliders) were placed in the modeled road to collect speed information equidistant to 10 meters along the 1225 meters of the virtual road section. The speed information collected in each collider combined with the positions of the traffic signs allowed us to track and study the speed changes according to the behavior of the participant in the simulation. The tests were performed using a steering wheel connected to a computer mounted in a cockpit to provide immersive driving within the simulation. This was complemented by a Head Mounted Display (HMD) - Oculus Rift ${ }^{\circledR}$ (Oculus / VR Headsets, Games \& Equipment, 2021) that provided to the user $360^{\circ}$ visualization of the virtual car and the road, shown in Figure 2A. This setup allows physical interaction and immersion (look and feel) to make the user completely involved in the simulated environment (Munafo, Diedrick and Stoffregen, 2017).

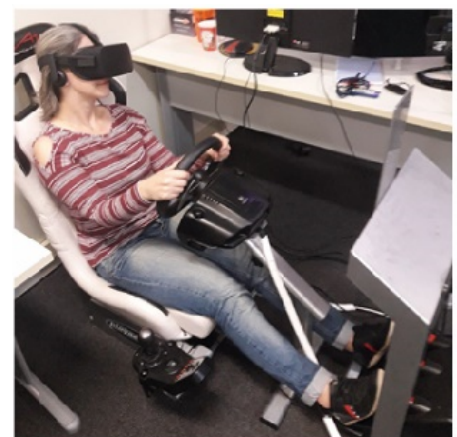

(a)

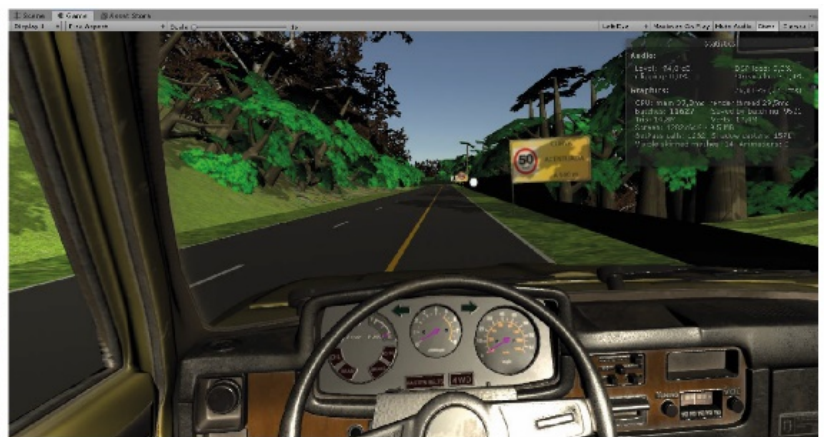

(b)

Figure 2. A) Driver using simulator B) Driver view in an immersive environment 
The simulation data were collected individually for each participant. Before each simulation, the phases of the present study were explained. First, the speed limits and car functioning were presented to the user. Into the simulation, each participant traveled a stretch to get used to the virtual environment and feel of the controls before entering the curved stretch. Students from the engineering department of our university participated voluntarily. To profile the participants, a questionnaire was applied asking age, gender, driving experience, and how many times they drive per week.

\subsection{Statistical Analysis}

Considering the speed of our main quantitative variable, to estimate the minimum sample size for the detection of statistically significant speed changes (if existent), it is necessary to know the standard variation (SD) of the speed that is performed in the real road stretch. Since this information is not available, we can use the six-sigma rule (Range $=$ Maximum - Minimum $=$ 6SD). Considering the experience of people that are used to drive on this road and a pilot sample in the simulator, the minimum, and maximum speed were estimated to be about $25 \mathrm{~km} / \mathrm{h}$ and $80 \mathrm{~km} / \mathrm{h}$, respectively. Therefore, the standard deviation would be smaller than $10 \mathrm{~km} / \mathrm{h}$. Knowing that the bigger the SD, the bigger the sample size, we considered an even larger SD of the speed in the curve, $15 \mathrm{~km} / \mathrm{h}$. Thus, for a confidence level of $95 \%$ and an error margin of $4 \mathrm{~km} / \mathrm{h}$, the computed minimum sample size was 55 participants. Thus, our sample was of 59 volunteer participants, who attended the inclusion criteria: age between 18 and 35 years old and own a driver's license. We tried to keep the approximate proportions of the sample according to the gender of the users of the road, for instance, more men than women. According to data from the National Traffic Department (Departamento Nacional de Trânsito - DENATRAN, 2021), 65\% of drivers in Brazil are men. However, considering the experiment was carried out in a university, accessing older volunteers was difficult.

Most of the participants had 18 to 25 years old, totaling $67.8 \%$. The rest of the participants with age between 26 and 35 years old accounted for $32.2 \%$. Regarding gender, $61.8 \%$ were men and $38.2 \%$ were women. Considering the time spent on driving, $47.5 \%$ drive more than five times per week, $22 \%$ drive one time per week or less, $15.25 \%$ drive between one and three times per week, and an equal amount drive four to five times per week. Analyzing the driver's experience, $47.5 \%$ have driver's license for five years or less, $42.4 \%$ have driver's license between five and ten years, and 10.2\% have driver's license over ten years. This profile information was obtained by a questionnaire, that was given to the participants inquiring about their age, gender and driving experience, and how many times they drive weekly.

To analyze the data collected, a Gaussian segmented linear regression was built as an extension of the linear model proposed by Quandt (1958) to estimate the difference in the average speed, the change in the slope (acceleration) for each gender and age as well as the difference in the slope between the profiles. It was considered that the change of speed does not necessarily happen in the exact position of the signalization, the change points can be considered in the proximity, depending on the data itself. Thus, the speed can be modeled at each position point $t$ (spaced every 10 meters) as:

$$
\boldsymbol{Y}_{\boldsymbol{t}}=\boldsymbol{\beta}_{\mathbf{0}}+\boldsymbol{\beta}_{W_{1}} \boldsymbol{X}_{\boldsymbol{t}}+\boldsymbol{\beta}_{W_{C_{1}}} \boldsymbol{X}_{\boldsymbol{t}}+\cdots+\boldsymbol{\beta}_{W_{C_{7}}} \boldsymbol{X}_{\boldsymbol{t}}+\boldsymbol{\beta}_{M_{0}}+\boldsymbol{\beta}_{M_{1}} D X_{\boldsymbol{t}}+\boldsymbol{\beta}_{M_{C_{1}}} D X_{\boldsymbol{t}}+\cdots+\boldsymbol{\beta}_{M_{C_{7}}} D X_{t}+\varepsilon_{t}(1)
$$
where $Y t$ is the observed speed at each position point $t$. $\beta_{0}$ represents the estimated average speed at the first point $(10 \mathrm{~m}) ; \beta_{W_{0}}$ is the estimated slope or trend of the speed before the first change point for the woman (W) group; $X t$ is the positions since the beginning of the stretch; 
$\beta_{W_{C_{1}}}$ represents the change in slope of the average speed after the first change point (A) $C 1$, while $\beta_{W_{C_{7}}}$ represents the change in slope of the average speed between the change points $G$ ( $7^{\text {th }}$ change point) and $H$ ( $8^{\text {th }}$ change point) (inside the stretch $=1$, otherwise $=0$ ) $\beta_{M_{0}}$ is the difference in the estimated average speed for men at the first point $(10 \mathrm{~m})$ in relation to the women group; $\beta_{M_{i}}$ is the difference in speed trend from men in relation to the women group in the $i$-th stretch; $D$ is a binary variable representing the gender (Woman $=0$, Men $=1$ ) or age group (18-25 = 0, 26-35 = 1), $\varepsilon t$ is the Gaussian error. This segmented model including gender or age variables considers the change point fixed prior to estimation. When necessary to estimate breakpoints, other regression models were built considering the breakpoints as parameters (Muggeo, 2003). The 95\% confidence intervals were also built to check if the moment of deceleration was different between the investigated groups (Muggeo, 2017).

Because of the dependence in the data, the model was built considering the same principles of time series modeling where the dependence is also natural. After the model estimation, the assumptions of the model were checked. All analyses were implemented in the $R$ language.

\section{RESULTS}

In this section, the results are evaluated by gender and age. First, the speed profiles are evaluated only by gender. Then, the profiles are separated by gender and age group (18 - 25 years old and 26 - 35 years old), and, finally, the profiles are separated only by age. Then, the results of the accidents are presented separated by age, gender, and driver's experience.

Analyzing the behavior of all drivers only by gender (Figure 3), it is observed that the trends in speed vary after each change point but not much difference is seen regarding gender. All trend changes $(\beta w)$ were statistically significant $(p$-value $<0.05)$ except for the stretch between 180 and $230 \mathrm{~m}$ (Table 1). No significant difference was detected in the male trend $\left(\beta_{\mathrm{M}}\right)$ or in the average level $\left(\beta_{\mathrm{M} 0}\right)$ ( $p$-value $\left.>0.05\right)$. On the other hand, in all simulated stretch, on average, the drivers had a slowdown and an acceleration at the same points (Figure 3). It was also noted a lower speed when the participants entered the curve in comparison to the rest of the stretch, but still higher than the road speed limit $(50 \mathrm{~km} / \mathrm{h})$, which may have been caused by a lack of real punishment for speeding.

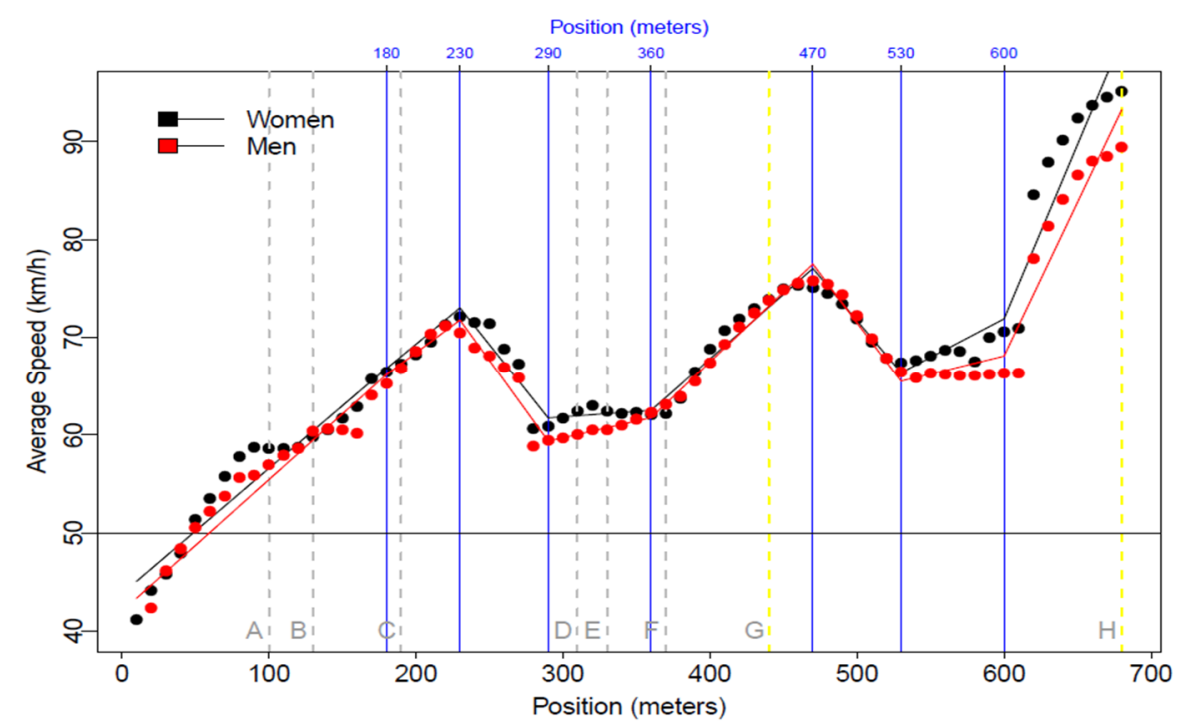

Figure 3. Speed variation by gender 
In the following graphs (Figure 3, Figure 4, Figure 5, and Figure 6) A, B, C, D, E, and F correspond to traffic warning signals. The stretch between $\mathrm{G}$ and $\mathrm{H}$ is where the sharp curve is (yellow vertical lines). In $G$, there is a radar speed trap $(50 \mathrm{~km} / \mathrm{h})$. The blue vertical lines indicate the position of the speed change points included in the segmented model. The speed limit of $50 \mathrm{~km} / \mathrm{h}$ is represented by the horizontal black line. In Figure 3, the average speed (points) by gender on each observed position is shown.

Table 1 - Estimates for the segmented model (women x men)

\begin{tabular}{|c|c|c|c|c|}
\hline Parameters & $\begin{array}{l}\text { Change Stretch } \\
\text { (meters) }\end{array}$ & Estimate & Standard Error & $\mathrm{p}$-Value \\
\hline $\boldsymbol{\beta}_{0}$ & 10 & 43.780 & 0.971 & $<0.001$ \\
\hline $\boldsymbol{\beta}_{W_{1}}$ & $10-180$ & 1.278 & 0.086 & $<0.001$ \\
\hline$\beta_{W_{C_{1}}}$ & $180-230$ & -0.033 & 0.353 & 0.927 \\
\hline $\boldsymbol{\beta}_{W_{C_{2}}}$ & $230-290$ & -3.130 & 0.527 & $<0.001$ \\
\hline $\boldsymbol{\beta}_{W_{C_{3}}}$ & $290-360$ & 1.996 & 0.449 & $<0.001$ \\
\hline $\boldsymbol{\beta}_{w_{C_{4}}}$ & $360-470$ & 1.211 & 0.315 & $<0.001$ \\
\hline$\beta_{W_{C_{5}}}$ & $470-530$ & -3.101 & 0.337 & $<0.001$ \\
\hline $\boldsymbol{\beta}_{W_{c_{6}}}$ & $530-600$ & 2.568 & 0.372 & $<0.001$ \\
\hline $\boldsymbol{\beta}_{W_{c_{7}}}$ & $600-700$ & 2.773 & 0.287 & $<0.001$ \\
\hline$\beta_{M_{0}}$ & 10 & -1.788 & 1.373 & 0.196 \\
\hline $\boldsymbol{\beta}_{M_{C_{1}}}$ & $10-180$ & 0.064 & 0.121 & 0.599 \\
\hline $\boldsymbol{\beta}_{M_{C_{2}}}$ & $180-230$ & -0.186 & 0.499 & 0.710 \\
\hline $\boldsymbol{\beta}_{M_{C_{3}}}$ & $230-290$ & -0.063 & 0.746 & 0.932 \\
\hline $\boldsymbol{\beta}_{M_{C_{4}}}$ & $290-360$ & 0.416 & 0.635 & 0.513 \\
\hline $\boldsymbol{\beta}_{M_{C_{5}}}$ & $360-470$ & -0.121 & 0.446 & 0.787 \\
\hline $\boldsymbol{\beta}_{M_{C_{6}}}$ & $470-530$ & -0.333 & 0.460 & 0.471 \\
\hline $\boldsymbol{\beta}_{M_{C_{7}}}$ & $530-600$ & -0.194 & 0.418 & 0.642 \\
\hline$R^{2}$ adjusted & & 0.964 & & \\
\hline
\end{tabular}

Figure 4 and Table 2 show the behavior of the drivers with age between 18 and 25 years old, which includes 40 participants, 24 men, and 16 women.

Analyzing Figure 4 and Table 2, it is observed that the group of young drivers participating in the study had a similar change in speed when approaching the curve. Both genders slowed after going through points $\mathrm{C}$ and $\mathrm{G}$. However, men decelerated more than women after point $\mathrm{G}$ (curve - position 470) with statistically significant slope difference of $-1.398 \mathrm{~km} / \mathrm{h}$ each 10 meters (significance level $=0.05$; $\mathrm{p}$-value $=0.002$ ). This represents a faster change of speed by young male drivers. After the change point in position 210, it is observed that men tended to slow down more than women reaching about $55 \mathrm{~km} / \mathrm{h}$ (change point in position 290 - about 80 meters later). The reductions from position 210 to 290 were on average $7.7 \mathrm{~km} / \mathrm{h}$ and 12.2 $\mathrm{km} / \mathrm{h}$ for women and men, respectively. After point $\mathrm{G}$, this fact was more evident where the reduction for men was double $(12.6 \mathrm{~km} / \mathrm{h})$ of the women $(6.3 \mathrm{~km} / \mathrm{h})$. While women presented an average speed of $70 \mathrm{~km} / \mathrm{h}$ at position 530, men were about $60 \mathrm{~km} / \mathrm{h}$.

Figure 5 shows the behavior of the drivers age between 26 and 35 years old, which includes 19 participants, 12 men, and 7 women. For this age group, in general, differently from the young drivers, men tend to drive at a higher velocity than women. In point 290 , the average speed was $53 \mathrm{~km} / \mathrm{h}$ for women and $66 \mathrm{~km} / \mathrm{h}$ for men. In the curve (point 530), the women reduced the speed to the average of $58.7 \mathrm{~km} / \mathrm{h}$ while the men's average speed at this point was $73 \mathrm{~km} / \mathrm{h}$. 
It is also noted that women tended to start the deceleration before men. As the change points in this model were included considering the woman group (Figure 5A), two new models were built to estimate each change point separately according to gender focusing only on the curve stretch. From the estimated change points as well as their confidence interval (CI) in Figure 5B, it is possible to confirm what was supposed Figure 5A (focus only on the analyzed interval before the curve at point 530) - women started to slow down 30 meters before men.

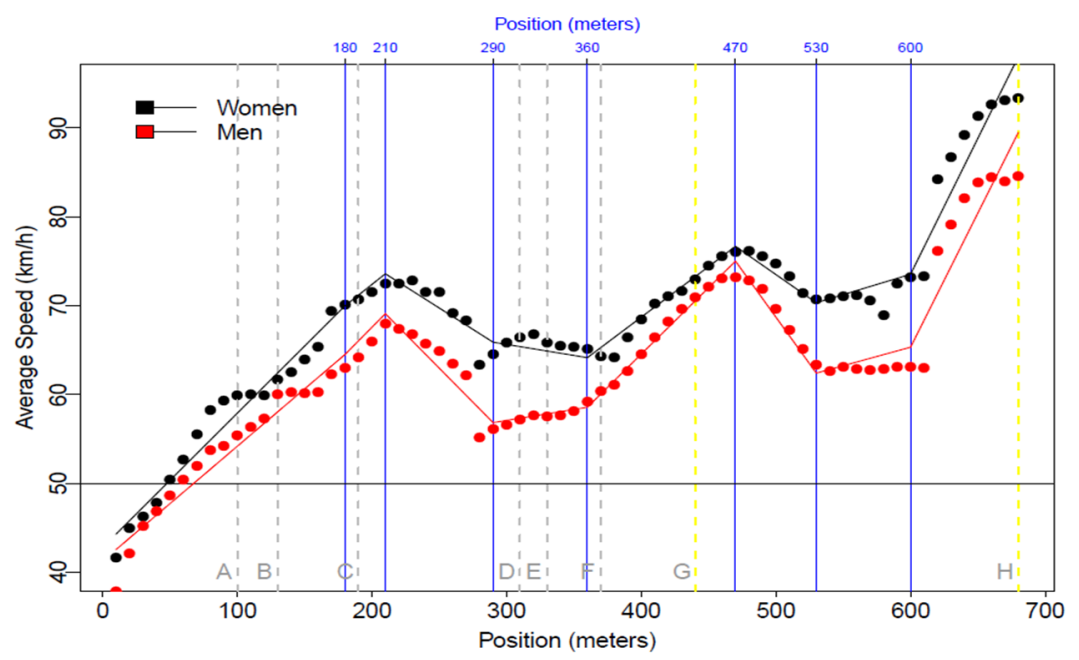

Figure 4. Speed variation from drivers between 18 and 25 years old

Table 2 - Estimates for the segmented model (age group from 18 to 25 years old)

\begin{tabular}{|c|c|c|c|c|}
\hline Parameters & $\begin{array}{c}\text { Change Stretch } \\
\text { (meters) }\end{array}$ & Estimate & Standard Error & $p$-Value \\
\hline$\beta_{0}$ & 10 & 42.775 & 0.940 & $<0.001$ \\
\hline$\beta_{W_{1}}$ & $10-180$ & 1.511 & 0.085 & $<0.001$ \\
\hline $\boldsymbol{\beta}_{W_{c_{1}}}$ & $180-230$ & -0.309 & 0.523 & 0.555 \\
\hline $\boldsymbol{\beta}_{W_{c_{2}}}$ & $230-290$ & -2.164 & 0.625 & 0.001 \\
\hline $\boldsymbol{\beta}_{W_{C_{3}}}$ & $290-360$ & 0.714 & 0.361 & 0.051 \\
\hline $\boldsymbol{\beta}_{w_{c_{4}}}$ & $360-470$ & 1.387 & 0.295 & $<0.001$ \\
\hline$\beta_{W_{C_{5}}}$ & $470-530$ & -2.195 & 0.323 & $<0.001$ \\
\hline $\boldsymbol{\beta}_{W_{C_{6}}}$ & $530-600$ & 1.515 & 0.356 & $<0.001$ \\
\hline $\boldsymbol{\beta}_{W_{C_{7}}}$ & $600-700$ & 2.603 & 0.275 & $<0.001$ \\
\hline$\beta_{M_{0}}$ & 10 & -1.519 & 1.329 & 0.255 \\
\hline $\boldsymbol{\beta}_{M_{C_{1}}}$ & $10-180$ & -0.220 & 0.120 & 0.069 \\
\hline $\boldsymbol{\beta}_{\boldsymbol{M}_{C_{2}}}$ & $180-230$ & 0.550 & 0.740 & 0.459 \\
\hline $\boldsymbol{\beta}_{M_{C_{3}}}$ & $230-290$ & -0.899 & 0.883 & 0.311 \\
\hline $\boldsymbol{\beta}_{M_{C_{4}}}$ & $290-360$ & 1.065 & 0.511 & 0.039 \\
\hline$\beta_{M_{C_{5}}}$ & $360-470$ & -0.139 & 0.417 & 0.739 \\
\hline $\boldsymbol{\beta}_{M_{C_{6}}}$ & $470-530$ & -1.398 & 0.440 & 0.002 \\
\hline $\boldsymbol{\beta}_{M_{C_{7}}}$ & $530-600$ & 1.001 & 0.400 & 0.014 \\
\hline \multicolumn{2}{|c|}{$R^{2}$ adjusted } & 0.966 & & \\
\hline
\end{tabular}

Besides, along the curve stretch, the speed changed more drastically for the female group. The men kept the average speed changing more smoothly. From Table 3 we can see that the speed slope was 2.193 and 2.424 larger for men than women (p-value $<0.05)$ after the positions 240 and 440. 
A)

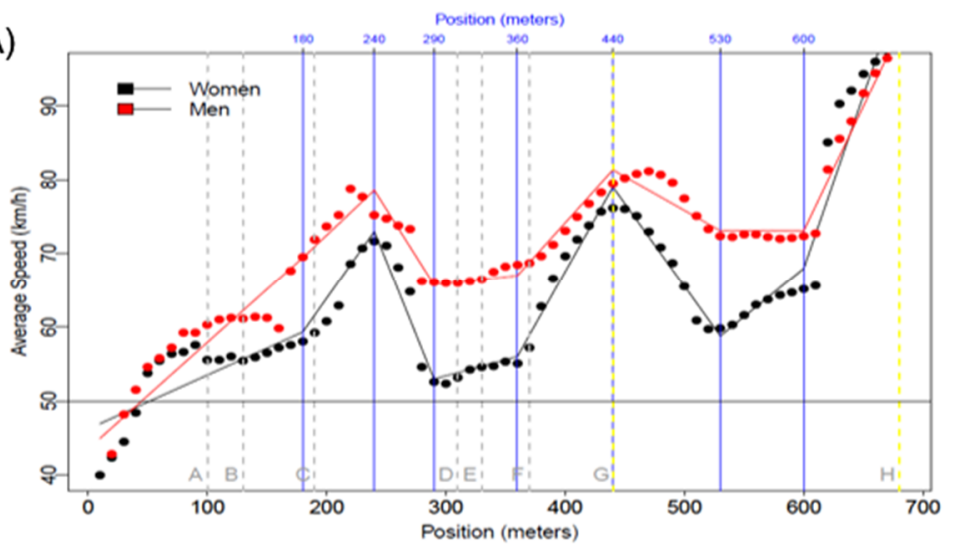

B)

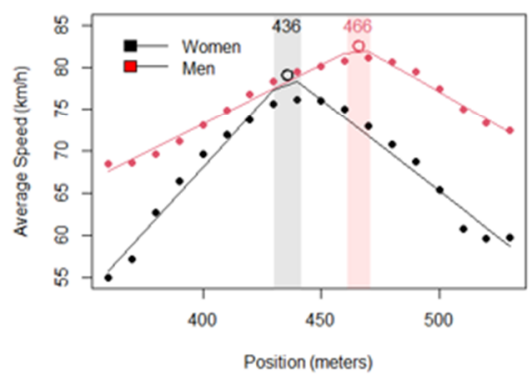

Figure 5. A) Segmented model considering fixed change points to compare speed variation according to gender from drivers between 26 and 35 years old. B) Models to estimated change points for speed variation for each gender from drivers between 26 and 35 years old (interval 360-530m)

Table 3 - Estimates for the segmented model (age group from 26 to 35 years old)

\begin{tabular}{|c|c|c|c|c|}
\hline Parameters & $\begin{array}{l}\text { Change Stretch } \\
\text { (meters) }\end{array}$ & Estimate & Standard Error & p-Value \\
\hline$\beta_{0}$ & 10 & 46.200 & 1.364 & $<0.001$ \\
\hline$\beta_{W_{1}}$ & $10-180$ & 0.727 & 0.119 & $<0.001$ \\
\hline$\beta_{W_{C_{1}}}$ & $180-230$ & 1.556 & 0.430 & $<0.001$ \\
\hline $\boldsymbol{\beta}_{W_{C_{2}}}$ & $230-290$ & -6.292 & 0.755 & $<0.001$ \\
\hline$\beta_{W_{C_{3}}}$ & $290-360$ & 4.445 & 0.726 & $<0.001$ \\
\hline $\boldsymbol{\beta}_{w_{c_{4}}}$ & $360-470$ & 2.441 & 0.530 & $<0.001$ \\
\hline$\beta_{W_{C_{5}}}$ & $470-530$ & -5.128 & 0.436 & $<0.001$ \\
\hline $\boldsymbol{\beta}_{W_{C_{6}}}$ & $530-600$ & 3.566 & 0.407 & $<0.001$ \\
\hline $\boldsymbol{\beta}_{W_{C_{7}}}$ & $600-700$ & 3.375 & 0.394 & $<0.001$ \\
\hline$\beta_{M_{0}}$ & 10 & -2.697 & 1.929 & 0.165 \\
\hline $\boldsymbol{\beta}_{M_{C_{1}}}$ & $10-180$ & 0.712 & 0.169 & $<0.001$ \\
\hline $\boldsymbol{\beta}_{M_{C_{2}}}$ & $180-230$ & -1.464 & 0.608 & 0.018 \\
\hline $\boldsymbol{\beta}_{\boldsymbol{M}_{C_{3}}}$ & $230-290$ & 2.193 & 1.067 & 0.042 \\
\hline$\beta_{M_{C_{4}}}$ & $290-360$ & -1.698 & 1.027 & 0.101 \\
\hline $\boldsymbol{\beta}_{M_{C_{5}}}$ & $360-470$ & -0.829 & 0.749 & 0.271 \\
\hline $\boldsymbol{\beta}_{M_{C_{6}}}$ & $470-530$ & 2.424 & 0.603 & $<0.001$ \\
\hline $\boldsymbol{\beta}_{M_{C_{7}}}$ & $530-600$ & -2.656 & 0.439 & $<0.001$ \\
\hline \multicolumn{2}{|c|}{$\mathrm{R}^{2}$ adjusted } & 0.948 & & \\
\hline
\end{tabular}

In addition, the average speed in the two age groups can be compared, as shown in Figure 6. From Figure 6A and Table 4, it can be observed that the older group tended to drive faster and slow down earlier in the curve. Thus, we built a model to estimate the change point as well as its confidence interval in the stretch $360-530 \mathrm{~m}$. From Figure 6B we can confirm what was supposed in Figure 6A (focus only on the analyzed interval before the curve at point 530), - the older group slowed down 20 meters before in the curve.

Despite the lower speed of the young drivers, this group had more accidents in the simulation (six of the seven accidents - 85.70\%). Furthermore, analyzing the number of accidents in relation to the driver gender, it is noted that five of the seven $(71.43 \%)$ were suffered by men and two by women. 


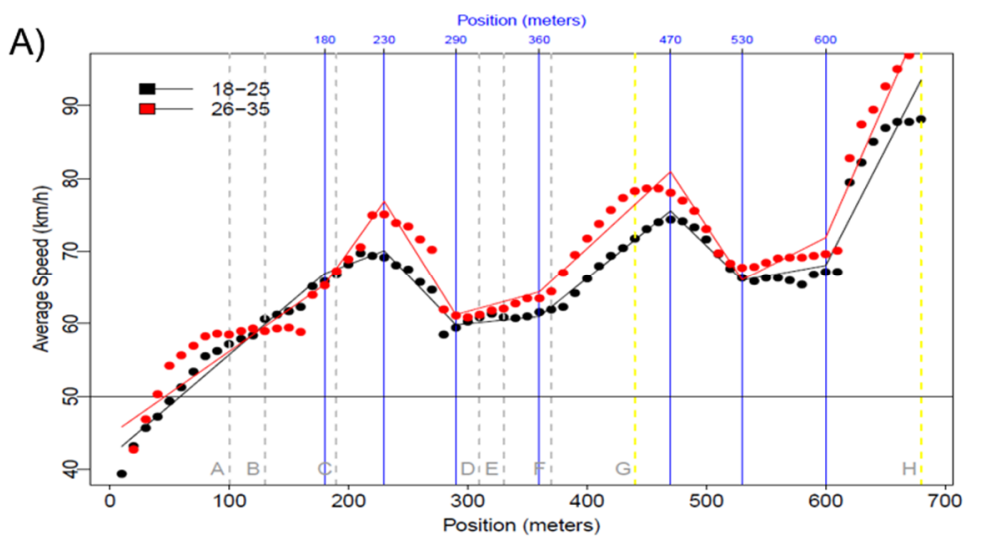

B)

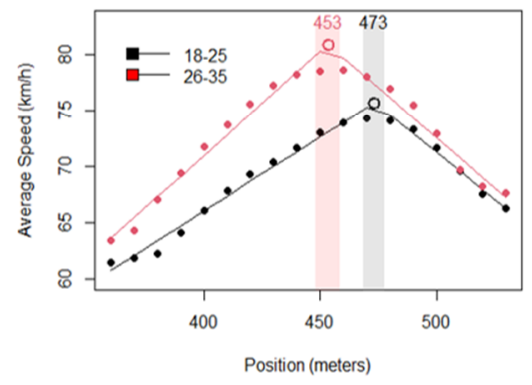

Figure 6. A) Segmented model considering fixed change points to compare speed variation by age. B) Models to estimated change points for speed variation for each age group (interval 360-530m).

Table 4 - Estimates from the segmented model (18 - 25 years old x 26 - 35 years old)

\begin{tabular}{ccccc}
\hline Parameter & $\begin{array}{c}\text { Change Stretch } \\
\text { (meters) }\end{array}$ & Estimate & Standard Error & p-Value \\
\hline $\boldsymbol{\beta}_{\boldsymbol{0}}$ & 10 & 41.747 & 1.072 & $<0.001$ \\
\hline $\boldsymbol{\beta}_{\boldsymbol{W}_{\boldsymbol{1}}}$ & $10-180$ & 1.397 & 0.095 & $<0.001$ \\
\hline $\boldsymbol{\beta}_{\boldsymbol{W}_{C_{1}}}$ & $180-230$ & -0.763 & 0.390 & 0.053 \\
\hline $\boldsymbol{\beta}_{\boldsymbol{W}_{\boldsymbol{C}_{2}}}$ & $230-290$ & -2.343 & 0.582 & $<0.001$ \\
\hline $\boldsymbol{\beta}_{\boldsymbol{W}_{\boldsymbol{C}_{3}}}$ & $290-360$ & 1.872 & 0.495 & $<0.001$ \\
\hline $\boldsymbol{\beta}_{\boldsymbol{W}_{C_{4}}}$ & $360-470$ & 1.164 & 0.348 & 0.001 \\
\hline $\boldsymbol{\beta}_{\boldsymbol{W}_{\boldsymbol{C}_{5}}}$ & $470-530$ & -2.919 & 0.372 & $<0.001$ \\
\hline $\boldsymbol{\beta}_{\boldsymbol{W}_{\boldsymbol{C}_{6}}}$ & $530-600$ & 1.886 & 0.410 & $<0.001$ \\
\hline $\boldsymbol{\beta}_{\boldsymbol{W}_{C_{7}}}$ & $600-700$ & 2.888 & 0.316 & $<0.001$ \\
\hline $\boldsymbol{\beta}_{\boldsymbol{M}_{\mathbf{0}}}$ & 10 & 2.924 & 1.516 & 0.056 \\
\hline $\boldsymbol{\beta}_{\boldsymbol{M}_{C_{1}}}$ & $10-180$ & -0.248 & 0.134 & 0.066 \\
\hline $\boldsymbol{\beta}_{\boldsymbol{M}_{C_{2}}}$ & $180-230$ & 1.916 & 0.551 & 0.001 \\
\hline $\boldsymbol{\beta}_{\boldsymbol{M}_{C_{3}}}$ & $230-290$ & -2.565 & 0.823 & 0.002 \\
\hline $\boldsymbol{\beta}_{\boldsymbol{M}_{C_{4}}}$ & $290-360$ & 1.182 & 0.700 & 0.094 \\
\hline $\boldsymbol{\beta}_{\boldsymbol{M}_{C_{5}}}$ & $360-470$ & -0.103 & 0.492 & 0.834 \\
\hline $\boldsymbol{\beta}_{\boldsymbol{M}_{C_{6}}}$ & $470-530$ & -1.072 & 0.507 & 0.037 \\
\hline $\boldsymbol{\beta}_{\boldsymbol{M}_{C_{7}}}$ & $530-600$ & 1.431 & 0.461 & 0.002 \\
\hline $\boldsymbol{R}^{2}$ adjusted & & 0.958 & 0.958 & 0.958 \\
\hline
\end{tabular}

\section{DISCUSSIONS}

Comparing the difference in the behavior of each driver profile, younger drivers take longer to start breaking, about 20 meters (Figure 6). In addition, it is possible to observe that drivers between 18 and 25 years old with up to five years of experience had more accidents in the simulations. This factor is associated with the reckless behavior and high confidence of these drivers, also identified in the research of Rhodes and Pivik (2011). In a similar work of Branzi, Domenichini and La Torre (2017), gender and age were evaluated both in VR in an urban road. The results found corroborated ours, showing that the driving experience influenced the overall speed and behavior of the participants. In Figure 6B, older drivers had a high speed in all simulations, but it is noted that the younger drivers acted belatedly. This fact may be linked to the lack of experience that is an important factor in the occurrence of accidents. A similar conclusion was identified by Clarke et al. (2006) and McCartt et al. (2009). 
When analyzing all participants, without differentiation by age, just by gender, it is noted that, in general, there is no relevant difference in the speed and behavior between the two groups (Figure 3). However, separating the groups by age, different behavior can be observed. In younger drivers (as mentioned earlier, the profile more prone to more aggressive and careless behavior), it is noted that women are more prone to drive faster along the stretch than men in this age group (Figure 4). Despite this higher speed (which can be considered more dangerous), men drove more irregularly (also considered dangerous). However, women showed a change in behavior after 26 years old. From Figure 5, it is noted that men in this group drive faster than women. When analyzing behavior before the curve (Figure 5B), which was measured by speed variation, it was observed that women from 26 to 35 years old decelerate before men. These behavior changes of women after 26 years old may indicate a cautious behavior or natural worrying that usually comes with time and experience. In men, this change was not observed in older drivers. In addition, women had fewer accidents than men in the simulations. This behavior change was also identified in the research of Roman et al. (2015), who specifies that the male gender and younger age have the most dangerous behavior, and by Clarke et al. (2006), who observed that young men driving on curves located on poorly-lit rural roads are more prone to accidents. The results are also confirmed from real data. On the route studied, most accidents were suffered by men.

An important detail perceived through the simulations is that the drivers traveled the route without taking much care about the speed limit and speed radars. For this, it can be observed that in all speed profiles (Figure 3, Figure 4, Figure 5 and Figure 6), the drivers' speed was higher than the speed limit. This behavior is imprecise and may be related to the lack of real punishment or real danger for drivers in the event of accidents because it is a virtual reality (VR). In addition, the simulated environment did not present continuous traffic and overcoming (other cars on the route were not considered in the study), relying only on the change of speed when approaching and leaving the curve.

\section{CONCLUSION}

Accident analysis is an important matter when proposing policies for road safety. However, experiments on real roads are dangerous. The use of VR driving simulators can bring great possibilities for studies that aim to replicate real environments. Thus, we built a VR simulation environment replicating a high-risky road stretch and carried out an experiment to analyze the speed-changing behavior of drivers regarding their gender and age. Furthermore, we intended to overcome the small sample sizes and limited analyses that have been performed in general in the literature. With segmented regression analysis, it was possible to evaluate the speed changes considering the gender and age factors in the models.

As a result, we found that younger drivers are more prone to accidents which relate to the data that was found by others research. In a general analysis, male and young drivers showed more aggressive and careless behavior. These results show that there are differences in driver's behavior concerning gender and age.

Considering that this research was developed in an engineering department of a university, one inherent limitation regards the inclusion of age groups older than 35 years. Future research could include older participants. However, our data of driver's gender fit well with the demographic data and the proportion of licensed drivers registered in the transit government department in Brazil. Also, future work can consider simulated traffic to analyze other causes 
of accidents like frontal collisions as well as perform comparisons between scenarios with and without signaling.

\section{ACKNOWLEDGEMENTS}

This research was partially funded by the Coordenação de Aperfeiçoamento de Pessoal de Nível Superior - Brasil (CAPES) Finance Code 001 (sponsorship to the third author), by National Council for Scientific and Technological Development (CNPq), and by PETROBRAS and ANP (4600556376 - sponsorship to the second author). Thanks to Gabriel Fernando Ritter and Roberto Korte Mentz for the technical support in the experimental development.

\section{REFERENCES}

Autodesk / Education Community (2021). Available at: https://www.autodesk.com.br/ (Accessed: July 15, 2021).

Bella, F. (2008) Driving simulator for speed research on two-lane rural roads, Accident Analysis \& Prevention. Pergamon, 40(3), pp. 1078-1087. doi: 10.1016/J.AAP.2007.10.015.

Bentley / OpenRoads - Transportation, Civil Analiys, Design Software (2021). Available at: https://www.bentley.com/ (Accessed: July 15, 2021).

Branzi, V., Domenichini, L. and La Torre, F. (2017) Drivers' speed behaviour in real and simulated urban roads - A validation study, Transportation Research Part F: Traffic Psychology and Behaviour. Pergamon, 49, pp. 1-17. doi: 10.1016/J.TRF.2017.06.001.

Chaudry, A. J. (2020) Human Behaviour in VR : Special automotive based environment Declaration of Originality. Tal Tech School of Information Technologies. Available at: https://digikogu.taltech.ee/testimine/en/Download/e759e6d3-55cd4f59-b48b-e162bf99ec3d/Inimkituminevirtuaalreaalsusesautojuhtiminee.pdf.

Clarke, D.D., Ward, P., Bartle, C., Truman, W. (2006) Young driver accidents in the UK: The influence of age, experience, and time of day, Accident Analysis \& Prevention. Pergamon, 38(5), pp. 871-878. doi: 10.1016/J.AAP.2006.02.013.

Comando Rodoviário da Brigada Militar - CRBM (2021). Available at: https://crbm.bm.rs.gov.br/resumo-de-acidentes/ (Accessed: July 15, 2021).

Dafrallah, S., Amine, A., Mousset, S., Bensrhair, A. (2020) Driver Behavior Assistance in Road Intersections, in Bhateja, V., Satapathy, S. C., and Satori, H. (eds.) Embedded Systems and Artificial Intelligence. Singapore: Springer Singapore, pp. 5360. doi: 10.1007/978-981-15-0947-6_6.

Departamento Nacional de Trânsito - DENATRAN (2021). Available at: https://www.gov.br/infraestrutura/ptbr/assuntos/denatran (Accessed: July 15, 2021).

Dickey, M. D. (2005) Three-dimensional virtual worlds and distance learning: two case studies of Active Worlds as a medium for distance education, British Journal of Educational Technology, 36(3), pp. 439-451. doi: https://doi.org/10.1111/j.1467-8535.2005.00477.x.

Farah, H., Zatmeh, S., Toledo, T., Wagner, P. (2016) Impact of distracting activities and drivers' cognitive failures on driving performance, Advances in Transportation Studies, 1, pp. 71-82. doi: 10.4399/978885489179107.

Goedicke, D., Li, J., Evers, V., \& Ju, W. (2018) VR-OOM: Virtual Reality On-ROad Driving SiMulation, in Proceedings of the 2018 CHI Conference on Human Factors in Computing Systems. New York, NY, USA: Association for Computing Machinery, pp. 111. Available at: https://doi.org/10.1145/3173574.3173739.

Ihemedu-Steinke, Q.C., Erbach, R., Halady, P., Meixner, G., Weber, M. (2017) Virtual Reality Driving Simulator Based on HeadMounted Displays BT - Automotive User Interfaces: Creating Interactive Experiences in the Car, in Meixner, G. and Müller, C. (eds.). Cham: Springer International Publishing, pp. 401-428. doi: 10.1007/978-3-319-49448-7_15.

Lee, J.H., Kwon, H., Choi, J., Yang, B.H. (2007) Cue-Exposure Therapy to Decrease Alcohol Craving in Virtual Environment, CyberPsychology |\& Behavior, 10(5), pp. 617-623. doi: 10.1089/cpb.2007.9978.

Lucas, F.R., Russo, L.E.A., Kawashima, R.S., Figueira, A.d.C., Larocca, A.P.C., Kabbach Jr, F.I. (2013) Uso de simuladores de direção aplicado ao projeto de segurança viária, Boletim de Ciências Geodésicas. Universidade Federal do Paraná, 19(2), pp. 341352. doi: 10.1590/S1982-21702013000200010.

Mannering, F. L., Shankar, V. and Bhat, C. R. (2016) Unobserved heterogeneity and the statistical analysis of highway accident data, Analytic Methods in Accident Research. Elsevier, 11, pp. 1-16. doi: 10.1016/J.AMAR.2016.04.001.

Matar, H. B. and Al-Mutairi, N. Z. (2020) Examining the factors affecting driver behavior in Metropolitan Kuwait, International Journal of Crashworthiness. Taylor \& Francis, 0(0), pp. 1-6. doi: 10.1080/13588265.2020.1773750.

McCartt, A.T., Mayhew, D.R., Braitman, K.A., Ferguson, S.A., Simpson, H.M. (2009) Effects of Age and Experience on Young Driver Crashes: Review of Recent Literature, Traffic Injury Prevention. Taylor \& Francis, 10(3), pp. 209-219. doi: $10.1080 / 15389580802677807$.

Meuleners, L. and Fraser, M. (2015) A validation study of driving errors using a driving simulator, Transportation Research Part F: Traffic Psychology and Behaviour. Pergamon, 29, pp. 14-21. doi: 10.1016/J.TRF.2014.11.009.

Morley, D. C., Lawrence, G. and Smith, S. (2016) Virtual Reality User Experience as a Deterrent for Smartphone Use While Driving, in Proceedings of the 9th ACM International Conference on PErvasive Technologies Related to Assistive Environments. New York, NY, USA: Association for Computing Machinery (PETRA '16). doi: 10.1145/2910674.2910696.

Muggeo, V. M. R. (2003) Estimating regression models with unknown break-points, Statistics in Medicine, 22(19), pp. 30553071. doi: https://doi.org/10.1002/sim.1545. 
Muggeo, V. M. R. (2017) Interval estimation for the breakpoint in segmented regression: a smoothed score-based approach, Australian |\& New Zealand Journal of Statistics, 59(3), pp. 311-322. doi: https://doi.org/10.1111/anzs.12200.

Munafo, J., Diedrick, M. and Stoffregen, T. A. (2017) The virtual reality head-mounted display Oculus Rift induces motion sickness and is sexist in its effects, Experimental Brain Research, 235(3), pp. 889-901. doi: 10.1007/s00221-016-4846-7.

Oculus / VR Headsets, Games \& Equipment (2021). Available at: https://www.oculus.com/ (Accessed: July 15, 2021).

Oeltze, K. and Schießl, C. (2015) Benefits and challenges of multi-driver simulator studies, IET Intelligent Transport Systems, 9(6), pp. 618-625. doi: https://doi.org/10.1049/iet-its.2014.0210.

Peng, X., Su, H., Wang, Z., \& Yu, Y. (2018) A Vehicle Driving Simulator Based on Virtual Reality, in CICTP 2018, pp. 2087-2097. doi: 10.1061/9780784481523.207.

Perrels, A., Votsis, A., Nurmi, V., Pilli-Sihvola, K. (2015) Weather Conditions, Weather Information and Car Crashes, ISPRS International Journal of Geo-Information. Multidisciplinary Digital Publishing Institute, 4(4), pp. 2681-2703. doi: 10.3390/ijgi4042681.

Quandt, R. E. (1958) The Estimation of the Parameters of a Linear Regression System Obeying Two Separate Regimes, Journal of the American Statistical Association. Taylor \& Francis, 53(284), pp. 873-880. doi: 10.1080/01621459.1958.10501484.

Rhodes, N. and Pivik, K. (2011) Age and gender differences in risky driving: The roles of positive affect and risk perception, Accident Analysis \& Prevention. Pergamon, 43(3), pp. 923-931. doi: 10.1016/J.AAP.2010.11.015.

Roman, G.D., Poulter, D., Barker, E., McKenna, F.P., Rowe, R. (2015) Novice drivers' individual trajectories of driver behavior over the first three years of driving, Accident Analysis \& Prevention. Pergamon, 82, pp. 61-69. doi: 10.1016/J.AAP.2015.05.012.

Savolainen, P.T., Mannering, F.L., Lord, D., Quddus, M.A. (2011) The statistical analysis of highway crash-injury severities: A review and assessment of methodological alternatives, Accident Analysis \& Prevention. Pergamon, 43(5), pp. 1666-1676. doi: 10.1016/J.AAP.2011.03.025.

Taheri, S.M., Matsushita, K., Sasaki, M. (2017) Virtual Reality Driving Simulation for Measuring Driver Behavior and Characteristics, Journal of Transportation Technologies. Scientific Research Publishing, 07(02), pp. 123-132. doi: 10.4236/jtts.2017.72009.

Tori, R., Kirner, C. and Siscoutto, R. (2006) Fundamentos e Tecnologia de Realidade Virtual e Aumentada Livro do VIII Symposium on Virtual Reality, Virtual Reality sumário, p. 422. Available at: http://romerotori.org/Sumario-LivroRV2006.pdf.

Unity Real-Time Development Platform / 3D, 2D VR \& AR Engine (2021). Available at: https://unity.com/ (Accessed: July 15, 2021).

Vieira, F. S. and Larocca, A. P. C. (2017) Drivers' speed profile at curves under distraction task, Transportation Research Part F: Traffic Psychology and Behaviour. Pergamon, 44, pp. 12-19. doi: 10.1016/J.TRF.2016.10.018.

World Health Organization - WHO (2018) Global Status Report on Road, World Health Organization, p. 20. Available at: http://apps.who.int/bookorders. 